\title{
Gamma Knife Radiosurgery of Cavernous Sinus Meningiomas: An Institutional Review
}

\author{
F.A. Zeiler, P.J. McDonald, A.M. Kaufmann, D. Fewer, J. Butler, \\ G. Schroeder, M. West
}

\begin{abstract}
Introduction: Stereotactic radiosurgery offers a unique and effective means of controlling cavernous sinus meningiomas with a low rate of complications. Methods: We retrospectively reviewed all cavernous sinus meningiomas treated with Gamma Knife (GK) radiosurgery between November 2003 and April 2011 at our institution. Results: Thirty patients were treated, four were lost to follow- up. Presenting symptoms included: headache (9), trigeminal nerve dysesthesias/paresthesias (13), abducens nerve palsy (11), oculomotor nerve palsy (8), Horner's syndrome (2), blurred vision (9), and relative afferent pupillary defect (1). One patient was asymptomatic with documented tumor growth. Treatment planning consisted of MRI and CT in 17 of 30 patients (56.7\%), the remainder were planned with MRI alone (44.3\%). There were 8 males $(26.7 \%)$ and 22 females (73.3\%). Twelve patients had previous surgical debulking prior to radiosurgery. Average diameter and volume at time of radiosurgery was $3.4 \mathrm{~cm}$ and $7.9 \mathrm{~cm}^{3}$ respectively. Average dose at the $50 \%$ isodose line was 13.5 Gy. Follow-up was available in 26 patients. Average follow-up was 36.1 months. Mean age 55.1 years. Tumor size post GK decreased in 9 patients (34.6\%), remained stable in 15 patients (57.7\%), and continued to grow in 2 (7.7\%). Minor transient complications occurred in 12 patients, all resolving. Serious permanent complications occurred in 5 patients: new onset trigeminal neuropathic pain (2), frame related occipital neuralgia (1), worsening of pre-GK seizures (1), and panhypopituitarism (1). Conclusion: GK offers an effective treatment method for halting meningioma progression in the cavernous sinus, with an acceptable permanent complication rate.
\end{abstract}

RÉSUMÉ: Radiochirurgie par scalpel gamma dans le méningiome du sinus caverneux: révision de dossiers dans une institution. Contexte : La radiochirurgie stéréotaxique offre un moyen unique et efficace de contrôle des méningiomes du sinus caverneux et comporte un faible taux de complications. Méthode : Nous avons révisé rétrospectivement tous les dossiers de patients atteints de méningiomes du sinus caverneux traités par radiochirurgie par scalpel gamme (SG) entre novembre 2003 et avril 2011 dans notre institution. Résultats : Trente patients, dont 8 hommes (26,7\%) et 22 femmes $(73,3 \%)$, ont été traités. Cependant, 4 ont été perdus de vue en cours de suivi. Les symptômes suivants étaient présents lors de la consultation initiale : une céphalée (9), des dysesthésies/paresthésies du trijumeau (13), une paralysie du nerf moteur oculaire externe (11), une paralysie du nerf moteur oculaire commun (8), un syndrome de Horner (2), une vision floue (9) et un déficit pupillaire afférent (1). Un patient était asymptomatique malgré la présence d'une tumeur dont le diagnostique était établi. Le plan de traitement a été établi à l'aide de l'IRM et de la tomodensitométrie chez 17 des 30 patients $(56,7 \%)$ et de l'IRM seule chez les autres $(44,3 \%)$. Douze patients ont subi une réduction chirurgicale du volume tumoral avant la radiochirurgie. Le diamètre moyen et le volume de la tumeur au moment de la radiochirurgie étaient de $3,4 \mathrm{~cm} \mathrm{et} 7,9 \mathrm{~cm}^{3}$ respectivement. La dose moyenne à la ligne isodose de 50\% était de 13,5Gy. Le suivi était disponible chez 16 patients. La durée moyenne du suivi était de 36,1 mois et l'âge moyen des patients était de 55,1 ans. La taille de la tumeur après traitement par SG a diminué chez 9 patients (34,6\%), est demeurée stable chez 15 patients $(57,7 \%)$ et a continué à croître chez 2 patients $(7,7 \%)$. Des complications transitoires mineures sont survenues chez 12 patients et toutes ces complications ont disparu. Cinq patients ont présenté des complications permanentes graves : une névralgie du trijumeau (2), une névralgie occipitale causée par le cadre stétéotaxique (1), une aggravation de crises convulsives préexistantes (1) et un panhypopituitarisme (1). Conclusion : Le SG est un mode de traitement efficace pour arrêter la progression du méningiome du sinus caverneux et son taux de complications permanentes est acceptable.

Can J Neurol Sci. 2012; 39: 757-762

Stereotactic radiosurgery (SRS) has afforded an effective technique in the treatment of skull base tumours, and has become an important addition to, or replacement of, microsurgical resection of these lesions. The unique ability to precisely focus external radiation sources and minimize radiation fall off on normal surrounding structures offers a minimally-invasive management option for cavernous sinus meningiomas. Linac, Cyberknife, and Gamma Knife (GK) based SRS have been shown to offer high rates of local tumour control with low complications $^{1-10}$. Of note is the substantial decrease in patient morbidity with GK compared to microsurgical resection ${ }^{11}$, with long term follow-up demonstrating good local control and functional independence ${ }^{12}$.

From the Section of Neurosurgery (FAZ, PJM, AMK, DF, MW), Dept of Surgery, Dept of Radiation Oncology (JB, GS), University of Manitoba, Winnipeg, Manitoba, Canada.

Received March 26, 2012. Final Revisions Submitted May 23, 2012. Correspondence to: Frederick A. Zeiler, Section of Neurosurgery, University of Manitoba, Health Sciences Center, GB-1 820 Sherbrook Street, Winnipeg, Manitoba, R3A 1R9, Canada. Email: umzeiler@cc.umanitba.ca. 
This study describes our institutional experience with GK stereotactic radiosurgery in the treatment of cavernous sinus meningiomas.

\section{METHODS}

Between November 2003 and April 2011, 30 patients with cavernous sinus meningiomas underwent GK radiosurgery at the Health Sciences Center in Winnipeg, Manitoba. We retrospectively reviewed the records of these patients and recorded data on: age, sex, tumour diameter and volume, GK treatment parameters, complications, time until tumour response, local control rates, and clinical outcomes. Local research ethics board approval was obtained prior to starting this study.

\section{RESUlts}

\section{Patient Demographics and Meningioma Characteristics}

All thirty patients received a single GK treatment at our institution and none had previous SRS at any other institution. Nineteen patients were treated with the Leksell Model C system, while eleven were treated with the Perfexion system. Of the thirty patients treated, twelve $(40 \%)$ had previous surgical debulking prior to GK radiosurgery, with an average time from surgery to GK of 34 months (range: eight months - six years). All patients demonstrated growth of the tumour upon post-surgical follow-up imaging prior to GK. The average patient age of the population was 55.1 years (range: 29 - 79), with $8(26.7 \%)$ being male and $22(73.3 \%)$ female. Mean follow-up time of all patients was 36.1 months (range: 3 - 80 months), with 4 patients $(13.3 \%)$ lost to follow-up, all residing in other provinces. Patient demographics are displayed in Table 1 . The data of those patients lost to follow-up can be seen in Table 2 .
Of the four patients lost to follow-up, all were referred to our facility by out of province physicians. They were subsequently lost to post-treatment follow-up after returning to their respective provinces.

Patients typically had multiple clinical symptoms at time of GK surgery including: diploplia (13), non-specific headache (9), ipsilateral trigeminal dysesthesias (13), blurred vision (9), Horner's syndrome (2), and new onset seizure (1). In one case the tumor was an incidental asymptomatic finding (1), with growth demonstrated on imaging follow-up. Neurological findings were also typically multiple in most patients, and consisted of: ipsilateral oculomotor nerve palsy (8), ipsilateral abducens nerve palsy (8), ipsilateral trigeminal nerve ophthalmic (8) and maxillary (6) hypoesthesia, ipsilateral Horner's syndrome (2), proptosis (1), temporal visual field cut (1), and a relative afferent pupilary defect (1).

Seventeen patients $(56.7 \%)$ had right sided cavernous sinus meningiomas, while thirteen $(43.3 \%)$ were left sided. Meningioma extensions included Meckel's cave (5), prepontine cistern (4), sellar/suprasellar (7), and middle fossa (3). Twelve patients $(40.0 \%)$ had partial cavernous internal carotid artery (ICA) encasement without vessel narrowing. Ten $(33.3 \%)$ patients had complete cavernous ICA encasement; only $2(6.7 \%)$ demonstrated ICA narrowing. Eight $(26.7 \%)$ patients had no direct magnetic resonance imaging (MRI) evidence of contact with the cavernous carotid. The average maximum diameter and volume of the tumour was $3.4 \mathrm{~cm}$ (range: $1.81-4.82 \mathrm{~cm}$ ) and 7.9 $\mathrm{cm}^{3}$ (range: $3.25-16.1 \mathrm{~cm}^{3}$ ) respectively.

A SRS grading scheme was developed in 2001 by DeSalles et $\mathrm{al}^{13}$ for cavernous sinus meningiomas. Grade I was described as lesions strictly in the cavernous sinus. Grade II cavernous sinus meningiomas extended to the clivus and/or the petrous bone,

Table 1: Demographic and treatment characteristics of patients with follow-up treated with Gamma Knife for Cavernous Sinus Meningioma

Demographic/Treamtment Category (n=26 Patients)

\begin{tabular}{lcc}
\hline \multicolumn{1}{c}{$\begin{array}{c}\text { Mex } \\
\text { Female }\end{array}$} & 7 \\
Age & 19 \\
Tumor Volume $\left(\mathrm{cm}^{3}\right)$ & $29-70$ (avg: 55.1$)$ \\
Avg Tumor Diameter $(\mathrm{cm})$ & $3.25-16.1$ (avg: 7.9$)$ \\
Avg \% Coverage & $1.81-4.82$ (avg: 3.4$)$ \\
Avg SRS Grade ${ }^{13}$ & 96.8 \\
Avg $50 \%$ Isodose Line dose (Gy) & 2.2 \\
Total Number with Local Control & $12.5-15$ (avg: 13.5$)$ \\
Total Number of Serious Complications & 24 \\
\hline
\end{tabular}

$\mathrm{n}=$ number, avg $=$ average, SRS $=$ stereotactic radiosurgery grade ${ }^{13}, \mathrm{~Gy}=$ Gray. Serious complications were defined as those that resulted in permanent deficits for the patient. 
Table 2: Characteristics of patients lost to follow-up

\begin{tabular}{lllll}
\hline Sex & Age & \multicolumn{1}{c}{ Presentation } & Location & Volume of Tumour $\left(\mathrm{cm}^{3}\right)$ \\
\hline $\mathrm{F}$ & 66 & Lt facial pain x 3 years, Diploplia & Left Cav Sinus & 13.6 \\
$\mathrm{M}$ & 51 & Lt retro-orbital pain, RAPD & Left Cav Sinus & 7.6 \\
$\mathrm{~F}$ & 71 & Rt vision loss, $3^{\text {ra }}$ nerve palsy & Right Cav Sinus & 4.6 \\
$\mathrm{~F}$ & 36 & Rt vision blurr, papilledema & Rt Cav Sinus, Orbital Apex & 3.6 \\
\hline F & &
\end{tabular}

$\mathrm{F}=$ female, $\mathrm{M}=$ male, $\mathrm{Lt}=$ left, $\mathrm{Rt}=$ right, $\mathrm{Cav}=$ cavernous

without compression of the brainstem. Grade III tumours had superior and/or anterior extension with compression of the optic nerve or tract. Grade IV lesions compressed the brain stem, and Grade V were bilateral lesions. We had eight patients with Grade I, seven patients with Grade II, six patients with Grade III, and five patients with Grade IV lesions. The average SRS grade in our study was 2.2 , with a range from 1 to 4 .

SRS treatment planning was performed using MRI and computed tomogram (CT) in $17(56.7 \%)$, and only MRI in 13 (43.3\%). Gamma Knife treatment parameters consisted of an average maximum tumour dose of $27.3 \mathrm{~Gy}$, with a range from 26 to $32.5 \mathrm{~Gy}$, and average number of collimator shots being 20.1 per treatment (range: $10-38$ ). Dose prescription was $13.5 \mathrm{~Gy}$ to the $50 \%$ isodose line, with a range from 12.5 to $15 \mathrm{~Gy}$. The average total volume covered (TVC) was $7.2 \mathrm{~cm}^{3}$ (range: $3.2-$ $16.3 \mathrm{~cm}^{3}$ ), with average percent coverage of $96.8 \%$ (range: $90-$ $100 \%)$. Twenty-eight $(93.3 \%)$ patients had a recorded dose including the optic apparatus that was on average 8.2 Gy (range: $3.4-11.7 \mathrm{~Gy}$ ), with four patients having a dose greater than 10 Gy.

Patients received post-treatment follow-up phone interviews at two weeks of GK treatment. Follow-up clinic visits were conducted six to eight weeks post treatment. Imaging was conducted at six months and yearly post treatment with MRI to assess tumour control and growth. Follow-up was available in 26 of 30 patients.

\section{Tumour Control}

Local control, which was defined as the absence of lesion growth or decrease in size on follow-up imaging occurred in 24/26 (92.3\%); 9 (34.6\%) demonstrated regression and $2(7.7 \%)$ displayed interval growth. Nineteen patients had a minimum two years of follow-up, with local control in 17 of 19 (89.5\%). Nine of these $19(47.4 \%)$ patients had tumour regression, while 8 of $19(42.1 \%)$ displayed stability and $2(10.9 \%)$ demonstrated growth.

Of the two patients with tumour growth, follow-up is continuing. One is asymptomatic, and the other has continuing issues with persisting facial numbness and new frame related occipital neuralgic pain.

\section{Complications}

Overall, complications occurred as a result of GK treatment in 17 of 26 patients $(65.4 \%)$. The majority of the complications were minor and transient effects seen in 12 patients (one patient had two): pin site infection (1), headache described as new or different from pre-treatment (7), pin site edema (3), right vision blurring (1), and ataxia (1). Serious complications, which we defined as those resulting in permanent deficits as a result of treatment occurred in 5 of 26 patients (19.2\%) and included: new trigeminal neuropathic pain (1), new occipital neuralgic pain related to frame placement (1), symptomatic cerebral edema/trigeminal neuropathic pain (1), worsening pre-treatment seizures (1), and panhypopituitarism (1). The patient with new onset trigeminal neuropathic pain post GK, had a $9.3 \mathrm{~cm}^{3}$ left meningioma extending into Meckle's cave and presented with left ophthalmic/maxillary trigeminal distribution numbness and partial abducens nerve dysfunction. Currently he remains with treatment refractory left $\mathrm{TN}$. The patient with new occipital neuralgic pain, developed this discomfort post stereotactic frame removal, and is likely a result of frame placement. The patient with minor symptomatic cerebral edema not requiring treatment and trigeminal neuropathic pain had a right $12.5 \mathrm{~cm}^{3}$ meningioma extending into Meckel's cave and presented with an oculomotor and abducens nerve dysfunction. No trigeminal nerve symptoms were present initially. Currently, he has ongoing atypical right sided facial discomfort in ophthalmic distribution of the trigeminal nerve, and slowly improving oculomotor and abducens nerve function. The patient with pre-GK seizures secondary to previous microsurgical debulking (three months previous to GK), had worsening post-GK seizures requiring a permanent increase in baseline dose of antiepileptic drug(s). Finally, the patient with panhypopituitarism had a $10.0 \mathrm{~cm}^{3}$ meningioma in the right cavernous sinus, sphenoid sinus and suprasellar cistern. Currently, this individual remains on cortisol, thyroid and testosterone replacement 63 months out from GK.

A MRI diagnosis of "central tumour radiation necrosis" occurred in 4 of $26(15.4 \%)$ patients, but was asymptomatic in all. None was confirmed with pathological specimens. One patient $(3.4 \%)$ developed localized asymptomatic cerebral edema on regular scheduled follow-up imaging.

When we review the control rates utilizing the SRS grading scheme developed by DeSalles et $\mathrm{al}^{13}$, the local control rates 
Table 3: Stereotactic radiosurgery grade ${ }^{13}$ and local control rates in patients with follow-up

\begin{tabular}{ccccc}
\hline SRS $^{13}$ Grade & Number of Patients & $\begin{array}{c}\text { \% of Tumours } \\
\text { Controlled }\end{array}$ & $\begin{array}{c}\text { \% of Tumours } \\
\text { Regressed }\end{array}$ & $\begin{array}{c}\text { Serious } \\
\text { Complications } \\
\text { (\%) }\end{array}$ \\
\hline 1 & 8 & 87.5 & 37.5 & 0 \\
2 & 7 & 100 & 28.6 & 28.6 \\
3 & 6 & 100 & 50.0 & 16.7 \\
4 & 5 & 80.0 & 20.0 & 20.0 \\
\hline
\end{tabular}

SRS $=$ stereotactic radiosurgery grade ${ }^{13}$. Serious complications were defined as those that resulted in permanent deficits for the patient.

were: Grade $1(n=8) 87.5 \%$ with three decreasing in size, Grade $2(n=7) 100 \%$ with two decreasing in size, Grade $3(n=6) 100 \%$ with three decreasing in size, and Grade $4(\mathrm{n}=5) 80.0 \%$ with one decreasing in size. Serious complication rates were $0 \%, 28.6 \%$, $16.7 \%$, and $20.0 \%$ respectively. Asymptomatic MRI declared "radiation effect" was documented in $12.5 \%, 14.3 \%, 16.7 \%$, and $20.0 \%$ respectively as seen in Table 3 .

\section{Symptom Control}

Overall average follow up was 36.1 months (range: $3-80$ ). Clinical improvement or stability of neurological symptoms occurred in 21 of the 26 patients $(80.8 \%)$. Fourteen patients had stable signs and symptoms, including: headache (4), trigeminal nerve dysfunction (only one with pain) (3), oculomotor and abducens combined (3), oculomotor nerve palsy and Horner's (1), Horner's (1), stable complex partial seizures on Tegretol (1), and right blurred vision (1). Six patients (23.1\%) had improvement of their pre-GK symptoms and included: trigeminal dysesthesias and abducens nerve palsy (1), headache (1), oculomotor nerve palsy (1), abducens nerve palsy (2), and trigeminal neuropathy/blurred vision (1). One patient developed gradual worsening of pre-existing seizures (seizures developed from previous surgical debulking and subsequent temporal lobe gliosis). Four patients developed new deficits post GK treatment, as described under the complications section. Finally, one patient remained asymptomatic throughout discovery, treatment, and follow-up.

In terms of Glasgow Outcome Scores (GOS) in those patients with follow-up, only four patients had a change in their pretreatment functional status. Four of the patients with a GOS of 4 were previously a GOS of 5 pre-treatment. These were those patients that developed serious complications as a result of their Gamma Knife treatment. The one patient with a GOS of 3 suffered worsening seizures related to temporal lobe gliosis from previous surgical resection, this not being a complication of GK.

\section{DISCUSSION}

Meningiomas of the cavernous sinus are a subset of skull base meningiomas that pose a treatment challenge. The location and surrounding critical anatomical structures provide a difficult environment for a standard open surgical approach. The presence of cranial nerves III, IV, V, and VI, in addition to the cavernous carotid artery and the surrounding carotid sympathetics, make this location challenging to operate in.
Prior to the microsurgical era, surgery for cavernous meningiomas resulted in high mortality and morbidity with the operative approaches available ${ }^{14}$. The watch and wait approach could also lead to significant morbidity due to multiple cranial neuropathies.

Through the advent of the operating microscope, advances in operative techniques, and further study into the anatomical relationships of the cavernous sinus ${ }^{15-18}$, a safer means of surgical management evolved.

Within the last 20 years many case series and operative series have been published demonstrating the efficacy of the open microsurgical approach to cavernous sinus meningiomas. Total resection rates varied from 12 to $80 \%$, with tumour control rates reported at 86 to $90 \%{ }^{19-24}$. However, operative mortality in some cases was as high as $7.3 \%$, with complications ranging up to $59.6 \%{ }^{11}$. Such described complications included: cranial nerve palsy (II, III, IV, V, VI), occlusion of the cavernous carotid artery, cerebrospinal fluid leak, and death. Thus, despite all the advances and developments which optimized current surgical techniques, a significant morbidity and mortality remain.

GK SRS has offered impressive local control rates from 91 up to $100 \%$, with complications ranging from 0 to $5 \%{ }^{3-10}$. Of note is the substantial decrease in mortality in the GK SRS patients, compared to the formal open microsurgical approach. With long term follow up, GK for cavernous meningiomas results in up to a $93.1 \%$ local control rate ${ }^{5}$, with up to an $88 \%$ patient functional independence rate ${ }^{12}$.

Being the only neurosurgical referral center in the province of Manitoba, has given us the ability to estimate yearly incidence and treatment rates on a population basis. Nineteen of 26 $(73.1 \%)$ of patients treated were Manitoba residents. We have follow-up data on all of these patients. Analyzing our data from 2003 - 2011, this would indicate a yearly incidence and treatment rate of 2.4 per million population (approximate population of Manitoba over last eight years since GK is $\sim 1$ million) in Manitoba.

Our experience so far demonstrates a good local control rate of $92.3 \%$, with $34.6 \%$ tumour regression rate. This is comparable to those rates described in the literature ${ }^{3-10}$. Furthermore, local control rate for SRS grade cavernous meningiomas I, II, II, and IV were $87.5 \%, 100 \%, 100 \%$, and $80.0 \%$ respectively, thus demonstrating control rates higher than predicted by De Salles' study ${ }^{13}$, though our follow-up is ongoing and not as extensive as demonstrated by De Salles' et al. 
In terms of greater than 24 month control, in those patients with minimum of 24 months follow-up, we achieved an $89.5 \%$ tumour stability/regression rate. Skeie et al ${ }^{12}$ demonstrate a long term control rate of $84.0 \%$ in patients with an average of 82 months of follow-up. Lee et $\mathrm{al}^{5}$ demonstrated a long term control rate of $93.1 \%$ at five and ten years for non-malignant meningiomas. Currently, the number of patients with greater than four years follow-up is small, and such extensive long term control conclusions cannot yet be made.

For those patients that demonstrated tumour growth despite GK, there weren't any specific tumor or treatment features that would indicate why there was a failure of response. Dosing and volume of treatment were within literature standard and not out of concert with those patients of ours who had demonstrated success post-GK. One could postulate that these lesions were not WHO grade I meningiomas at the time of GK. This may explain their resistance to the dosage applied. However, without pathology at the time of GK, we will never know.

Overall, our complication rate was high, at 16 out of 26 . Of note though, the majority of the complications recorded were minor and transient in nature (12 of the 16). Permanent complications affected 5 of 26 patients $(19.2 \%)$. This is higher than most series published in the literature to date. These complications stem from tumour location in 3 of the 4 , resulting in panhypopituitarism and two with trigeminal neuropathic pain. The fourth stemmed from a rare complication of stereotactic frame placement, leading to persistent occipital neuralgia.

With such an elevated complication rate, one may argue the $50 \%$ isodose line dosage should be decreased. However, the majority of the complications were transient in nature. The permanent complications are the ones of real concern. Future treatment of these lesions close to the pituitary will have to be considered, and optimization of the dose to the infundibulum may circumvent the endocrine dysfunction post-GK. In terms of the new cranial neuropathy post-GK, our dosing is within recommendations for skull base meningiomas, and further dose reduction in these areas would increase the risk of treatment failure, subjecting the patient to further repeat SRS treatment and the complications associated with that. Overall, our permanent complication rate is high, but within reason considering the morbidity associated with microsurgery and our high tumor control rates.

Upon further analysis of the new trigeminal neuropathic pain post GK, one patient had presenting complaints of trigeminal numbness. This raises the question as to whether pre-treatment trigeminal nerve complaints predispose to post-treatment complications of neuropathic pain. We had trigeminal nerve complaints in 13 patients, with two demonstrating improvement, and 8 indicating stable nature of their symptoms post treatment. Finally, given that only one of the two new post treatment neuropathic pain patients had presenting complaints of trigeminal dysesthesias, we cannot make definitive comments on the relationship of SRS and pre-treatment trigeminal nerve symptoms at this time.

Optic apparatus preservation rate post SRS was high in our series, with no patients demonstrating worsening visual function as a result of treatment. Of all patients treated, we had an average ON dose of $8.2 \mathrm{~Gy}$, considered well within the tolerance of the optic apparatus ${ }^{4,25}$.
We did reduce dosing in areas close to the optic apparatus and brainstem, in order to minimize the risk of post-GK optic neuropathy and brainstem injury.

Good results with GK in the treatment of cavernous sinus meningiomas are attributable to the following factors. First, we modelled our treatment planning according to the pre-existing groundwork done in the area of SRS in the cavernous sinus, in order to minimize complications and maximize tumour control. Second, we used the cavernous sinus SRS feasibility studies by De Salle ${ }^{26}$, and dose recommendations by Tishler ${ }^{27}$, Leber ${ }^{4}$, $\mathrm{Chen}^{28}$ and $\mathrm{Kenai}^{25}$. This offered safe recommendations as to a maximum cavernous sinus dose of 30-40 Gy and optic apparatus dosing less than $8 \mathrm{~Gy}$ that we could follow. Third, the addition of the cavernous meningioma grading system designed for stereotactic radiosurgery ${ }^{13}$, gave us the ability to predict pretreatment, the likelihood of local tumour control, and modify treatment planning respectively. Finally, vigilant attempts at maintaining tumour conformality during treatment planning and utilizing multiple collimator shots allowed us to target the meningioma volume effectively and to minimize radiation fall out to surrounding vital structures.

\section{Conclusion}

In our experience, GK SRS offers good local control rates with acceptable complication rates, comparable to those already defined in the literature. Given the centralization of neurosurgical services in Manitoba, this study has afforded us the ability to determine population based incidence and treatment rates for cavernous sinus meningiomas. Based on our provincial service, we expect 0.24 cases per 100,000 population per year. Ongoing management of cavernous sinus and parasellar meningiomas will continue to rely on SRS to provide local control with acceptable complication rates.

\section{REFERENCES}

1. Dolenc VV, Kregar T, Ferluga M, et al. Treatment of tumors involving the cavernous sinus. In Dolenc VV, editor. The cavernous sinus: a multidisciplinary approach to vascular and tumorous lesions. New York: Springer-Verlag; 1987. p 377-91.

2. Spiegelmann R, Nissim O, Menhel J, et al. Linear accelerator radiosurgery for meningiomas in and around the cavernous sinus. Neurosurgery. 2002; 51(6):1373-80.

3. Iwai Y, Yamanaka K, Ishiguro T. Gamma knife radiosurgery for the treatment of cavernous sinus meningiomas. Neurosurgery. 2003; 52(3):517-24.

4. Leber KA, Berglöff J, Pendl G. Dose-response of the visual pathways and cranial nerves of the cavernous sinus to stereotactic radiosurgery. J Neurosurg. 1998; 88:43-50.

5. Lee JKY, Niranjan A, McInernery J, et al. Stereotactic radiosurgery providing long-term control of cavernous sinus meningiomas. J Neurosurg. 2002; 97:65-72.

6. Morita A, Coffey RJ, Foote RL, et al. Risk of injury to cranial nerves after gamma knife radiosurgery for skull base meningiomas: Experience in 88 patients. J Neurosurg. 1999; 90: 42-9.

7. Nicalato A, Foroni R, Alessandrini F, et al. Radiosurgical treatment of cavernous sinus meningiomas: experience with 122 treated patients. Neurosurgery. 2002; 51(5):1153-61.

8. Roche PH, Régis J, Dufour H, et al. Gamma knife radiosurgery in the management of cavernous sinus meningiomas. J Neurosurg. 2000; 93(Suppl 3):68-73.

9. Shin M, Kurita H, Sasaki T, et al. Analysis of treatment outcome after stereotactic radiosurgery for cavernous sinus meningiomas. J Neurosurg. 2001; 95:435-9. 
10. Subach BR, Lunsford D, Kondziolka D, et al. Management of petroclival meningiomas by stereotactic radiosurgery. Neurosurgery. 1998; 42:437-45.

11. Sughrue ME, Rutkowski MJ, Aranda D, et al. Factors affecting outcome following treatment of patients with cavernous sinus meningiomas. J Neurosurg. 2010; 113:1087-92.

12. Skeie BS, Enger PO, Skeie GO, et al. Gamma knife surgery of meningiomas involving the cavernous sinus: long-term follow up of 100 patients. Neurosurgery. 2010; 66(4):661-8.

13. De Salles AA, Firghetto L, Grande CV, et al. Radiosurgery and stereotactic radiation therapy for skull base meningiomas: proposal of a grading system. Stereotact Funct Neurosurg. 2001; 76(3-4):218-29.

14. Cushing H, Eisenhardt L. Meningiomas: their classification, regional behavior, life history, and surgical end results. Baltimore: Springfield; 1938.

15. Forrester JM. The marvellous network and the history of enquiry into its function. J Hist Med Allied Sci. 2002; 57(2):198-217.

16. Knosp EG, Muller G, Pernecsky A. Anatomical remarks on the fetal cavernous sinus and on the veins of the middle cranial fossa. In: Dolenc VV, editor. The cavernous sinus. New York: SpringerVerlag; 1987. p. 104-16.

17. Parkinson D. Lateral sellar compartment O.T. (cavernous sinus): history, anatomy, terminology. Anat Rec. 1998; 251(4):486-90.

18. Parkinson D. Rete Mirable-The marvellous network. J Can Sci Neurol. 1974; 1:121-3.

19. Abdel-Aziz KM, Froelich SC, Dagnew E, et al. Large sphenoid wing meningiomas involving the cavernous sinus: conservative surgical strategies for better functional outcomes. Neurosurgery. 2004; 54:1375-83.
20. Cusimano MD, Sekhar LN, Sen CN, et al. The results of surgery for benign tumors of the cavernous sinus. Neurosurgery. 1995; 37:1-10.

21. De Jesus O, Sekhar LN, Parikh HK, et al. Long-term follow-up of patients with meningiomas involving the cavernous sinus: recurrence, progression, and quality of life. Neurosurgery. 1996; 39:915-20.

22. DeMonte F, Smith HK, al-Mefty O. Outcome of aggressive removal of cavernous sinus meningiomas. J Neurosurg. 1994; $81: 245-51$

23. O'Sullivan MG, van Loveren HR, Tew JM Jr. The surgical resectability of meningiomas of the cavernous sinus. Neurosurgery. 1997; 40:238-47.

24. Sindou M, Ernesto W, Jouanneau E, et al. Long-term follow-up of meningiomas of the cavernous sinus after surgical treatment alone. J Neurosurg. 2007; 107:937-44.

25. Kenai $H$, Yamashita M, Nakamura $T$, et al. Tolerance dose in Gamma Knife surgery of lesions extending to the anterior visual pathway. J Neurosurg. 2005; 102(Suppl):230-3.

26. De Salles AA, Bajada CL, Goetsch S, et al. Radiosurgery of the cavernous sinus. Acta Neurochir Suppl (Wein). 1993; 58:101-3.

27. Tishler RB, Loeffler JS, Lunsford LD, et al. Tolerance of cranial nerves of the cavernous sinus to radiosurgery. Int J Radiat Onc Biol Phys. 1993; 27(2):215-21.

28. Chen JCT, Giannotta SL, Yu C, et al. Radiosurgical management of benign cavernous sinus tumors: Dose profiles and acute complications. Neurosurgery. 2001; 48(5):1022-32. 